Abstracta Iranica

Revue bibliographique pour le domaine irano-aryen

Volume 34-35-36 | 2017

Comptes rendus des publications de 2011-2013

\title{
Philippe Gignoux, Christelle Jullien, Florence Jullien. Noms propres syriaques d'origine iranienne
}

\section{Philip Huyse}

\section{Q OpenEdition \\ 1 Journals}

\section{Édition électronique}

URL : http://journals.openedition.org/abstractairanica/41999

DOI : 10.4000/abstractairanica.41999

ISSN : 1961-960X

Éditeur :

CNRS (UMR 7528 Mondes iraniens et indiens), Éditions de l'IFRI

Référence électronique

Philip Huyse, « Philippe Gignoux, Christelle Jullien, Florence Jullien. Noms propres syriaques d'origine iranienne », Abstracta Iranica [En ligne], Volume 34-35-36 | 2017, document 3, mis en ligne le 30 juillet 2017, consulté le 28 septembre 2020. URL : http://journals.openedition.org/abstractairanica/41999 DOI : https://doi.org/10.4000/abstractairanica.41999

Ce document a été généré automatiquement le 28 septembre 2020.

Tous droits réservés 


\title{
Philippe Gignoux, Christelle Jullien, Florence Jullien. Noms propres syriaques d'origine iranienne
}

\author{
Philip Huyse
}

\section{RÉFÉRENCE}

Philippe Gignoux, Christelle Jullien, Florence Jullien. Noms propres syriaques d'origine iranienne. Vienne, Verlag der Österreichischen Akademie der Wissenschaften, 2009, 191 p. (Iranisches Personennamenbuch. Band VII. Iranische Namen in semitischen Nebenüberlieferungen. Faszikel 5 ; SbÖAW 789)

1 Avec gratitude, les spécialistes de l'onomastique iranienne salueront la parution d'un nouveau fascicule dans le cadre du grand dictionnaire onomastique iranien, publié sous les égides de l'Académie des Sciences autrichienne. Largement méconnus jusqu'ici, les noms syriaques d'origine iranienne n'avaient jamais fait l'objet d'une étude d'ensemble. Christelle et Florence Jullien se sont chargées du dépouillement d'un corpus considérable de textes syriaques entre les débuts de la christianisation et le XIII ${ }^{\mathrm{e}}$., représentant au total plusieurs milliers de pages. Les lecteurs seront d'autant plus reconnaissants aux éditrices pour cet important effort de récolement que la plupart des sources n'ont jamais été traduites dans une langue occidentale. De son côté, Philippe Gignoux a pris pour son compte l'interprétation étymologique des données.

$2 \mathrm{Au}$ total, le volume présente 477 entrées (sans compter les subdivisons proposographiques pour les nombreux porteurs d'un même nom). Il comprend un utile tableau de correspondances entre graphèmes syriaques et phonèmes moyen-perses ( $p$. 11-12), dont on note toutefois qu'il diverge parfois du traitement très complet de la question (chap. 11, en particulier, p. 69-88) par Claudia Ciancaglini dans son livre sur les mots d'emprunt iraniens en syriaque (voir Abs. Ir. 31, 2008, c.r. $n^{\circ} 205$ ). Les noms compris dans le corpus sont pour la plupart déjà connus grâce aux différentes sources 
moyen-perses ; les explications étymologiques sont très succinctes et auraient parfois méritées une analyse plus poussée, en particulier quand il s'agit de formes présentant une graphie déviante de celle que l'on attendrait.

\section{AUTEURS}

PHILIP HUYSE

EPHE 